Michael J. Chan

\title{
The Wealth of Nations
}

\section{A Tradition-Historical Study}

[Der Reichtum der Völker. Eine traditionsgeschichtliche Untersuchung.]

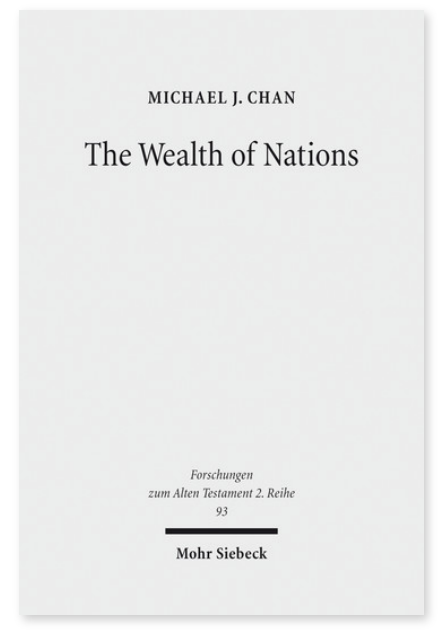

2017. XVI, 273 Seiten. FAT II 93

ISBN 978-3-16-154543-6

DOI 10.1628/978-3-16-154543-6

eBook PDF 104,00€

ISBN 978-3-16-154098-1

fadengeheftete Broschur 104,00€
Veröffentlicht auf Englisch.

Michael J. Chan setzt sich auf methodologischer Ebene dafür ein, ikonographisches Material stärker in Fragen der Traditionsgeschichte (eine Methode, die sich meist allein auf Textbelege konzentriert) zu berücksichtigen. Im Anschluss an O.H. Steck muss der Begriff »Tradition« weiter gefasst werden, damit er sich auf vererbte Konzepte und Konstellationen bezieht, welche sich über verschiedene Medien erstrecken können. Der Autor untersucht anhand traditionsgeschichtlicher Methodik die »Reichtum der Völker «-Tradition - eine Reihe von Texten, in denen die anderen Völker der Erde ihren Reichtum nach Zion bringen. Die Tradition des Reichtums der Völker war im gesamten Nahen Osten der Antike verbreitet. Michael J. Chan zeigt, dass die biblischen Texte diese Tradition manchmal mit kaum einer oder ohne Veränderung widerspiegeln, wohingegen sie in anderen Fällen in erfinderischer oder sogar zerstörerischer Art und Weise umgestaltet wird.

Michael J. Chan Born 1982; 2012 Research/Teaching Grant at the University of Helsinki; 2013 PhD in Hebrew Bible from Emory University; formerly Assistant Professor of Old Testament, Luther Seminary; currently Pastor of Grace Lutheran Church, Kingman, AZ.

\section{Jetzt bestellen:}

https://mohrsiebeck.com/buch/the-wealth-of-nations-9783161545436?no_cache=1

order@mohrsiebeck.com

Telefon: +49 (0)7071-923-17

Telefax: $+49(0) 7071-51104$ 